\title{
A PRODUÇÃO TEXTUAL EM CLASSES DE EDUCAÇÃO DE JOVENS, ADULTOS E IDOSOS: ALGUMAS PROBLEMATIZAÇÕES
}

RESUMO: Este trabalho tem o objetivo de apresentar algumas reflexões sobre as atividades de produção textual na Educação de Jovens, Adultos e Idosos (EJAI). O artigo é um recorte da pesquisa de doutorado que visou conhecer algumas percepções dos educandos e educadores sobre os processos de aprendizagem da leitura, escrita e oralidade na EJAI, considerando as singularidades dos sujeitos e estabelecendo relações com os usos sociais da língua. Para o desenvolvimento deste estudo, foi feita uma pesquisa etnográfica numa escola da rede pública estadual do município de Salvador. Foram realizadas entrevistas semiestruturadas com discentes e professores, além de observações de aula. A partir dos resultados da pesquisa, foi possível perceber que o ditado e a cópia aparecem em destaque como exercício de escrita nessas classes. No entanto, emerge, ainda que timidamente, a demanda por práticas de escrita mais contextualizadas. Espera-se que este trabalho contribua para uma qualificação do olhar sobre o ensino da escrita na EJAI e destaca-se ainda a importância de ouvir atentamente os sujeitos nos momentos de repensar a educação ofertada nessa modalidade de ensino.

Palavras-chave: Produção textual na EJAI. Ditado. Cópia. Práticas contextualizadas.

\section{Introdução}

Gastei uma hora pensando em um verso que a pena não quer escrever. No entanto ele está cá dentro inquieto, vivo.

Ele está cá dentro e não quer sair.

Mas a poesia deste momento inunda minha vida inteira.

Drummond

“O verso está aqui dentro, inquieto, vivo e não quer sair, a pena não quer escrever”. Esse trecho do poema do Drummond nos remete aos desafios enfrentados pelas pessoas que escrevem cotidianamente. Pensar o texto, escolher as palavras, corrigir, travar, recomeçar, reescrever são rotinas que perpassam o exercício de produção textual. Há inspiração que às vezes não vem, há palavras que não saem e há ideias que estão em nossas cabeças, mas que a "pena", ou a caneta, ou a tecla do computador não querem escrever. As pessoas que

\footnotetext{
* Doutora em Educação pela Universidade Federal da Bahia (Ufba). Professora Adjunta da Universidade Federal do Recôncavo da Bahia (UFRB).
} 
possuem a escrita em sua rotina sabem que esses comportamentos escritores são recorrentes no exercício de produção textual e que, a partir deles, tecemos as belezuras dos textos que escrevemos.

Ferreiro (1995, p.103) nos diz que "A língua escrita é muito mais que um conjunto de formas gráficas. É um modo de a língua existir, é um objeto social, é parte de nosso patrimônio cultural". Nessa perspectiva, ressaltamos que é na escola que os discentes vão aprender essa outra forma de se expressar, assumir o papel de produtores e leitores de textos em que os domínios básicos sobre as convenções sociais da língua vão se desenvolver.

Entretanto, ainda observamos, em contextos escolares, práticas de escrita que não coadunam com o exercício de produção textual e, por vezes, limitam e empobrecem a formação de sujeitos escritores. Por outro lado, esses mesmos contextos surpreendem e nos apresentam essa formação num exercício colaborativo e solidário, no âmbito dos usos sociais da escrita.

Nesse sentido, este trabalho ${ }^{1}$ pretende apresentar algumas problematizações em torno da produção textual na Educação de Jovens, Adultos e Idosos, especialmente propondo reflexões sobre o ditado e a cópia como exercício de escrita. O artigo é um recorte da pesquisa de doutorado ${ }^{2}$ que visou conhecer algumas percepções dos educandos e educadores sobre os processos de aprendizagem da leitura, escrita e oralidade na EJAI, considerando as singularidades dos sujeitos e estabelecendo relações com os usos sociais da língua. Para o desenvolvimento deste estudo, fiz uma pesquisa etnográfica numa escola da rede pública de ensino. Para este artigo, apresentarei algumas discussões sobre as percepções de docentes e discentes acerca do processo de aprendizado da escrita nas classes da EJAI, considerando o contexto pesquisado e as subjetividades dos atores envolvidos.

\section{Considerações metodológicas}

Para a realização deste trabalho, optei por fazer uma pesquisa etnográfica em uma escola da rede pública estadual do município de Salvador. A escola se destaca por ser um Centro de EJAI, em que funciona a Educação de Jovens, Adultos e Idosos nos turnos matutino, vespertino e noturno e também em toda a Educação Básica.

\footnotetext{
${ }^{1}$ A primeira versão deste texto foi publicada nos anais Anais do III CONBAlf - Congresso Brasileiro de Alfabetização: diálogos sobre alfabetização, realizado na cidade de Vitória- ES, Congresso realizado no período de 16 a 18 de julho de 2017.

${ }^{2}$ SILVA. Erica Bastos da. Aprendizagem da leitura, escrita e oralidade na EJA: Um olhar sobre percepções e práticas na EJA. 201f.Tese (Doutorado). Faculdade de Educação, Universidade Federal da Bahia, 2016. Disponível em: https://repositorio.ufba.br/ri/handle/ri/19879, acesso em 10/11/2020.
} 
Nos limites deste artigo, não farei detalhamentos longos sobre o trabalho de campo, mas reitero que busquei ouvir os sujeitos, com seus falares, desejos, saberes e afetos. Nesse exercício, quis ouvi-los, atentando para suas demandas educativas, para que essa escuta sensível pudesse propiciar reflexões sobre a educação ofertada na EJAI, abarcando, assim, as suas complexidades.

O trabalho de campo durou seis meses (de junho de 2014 a janeiro de $2015^{3}$ ) e aconteceu em duas turmas do Tempo Formativo I que estão em processo de alfabetização, contemplando as duas professoras e 14 discentes. Nesse período, pude conviver e aprender com os sujeitos por meio de entrevistas, conversas informais e observações de aula. Nesse sentindo, os posicionamentos críticos emergiram por meio da convivência, bem como as percepções dos sujeitos sobre seus aprendizados naquele espaço.

Para fazer a análise dos dados coletados, utilizei a análise do conteúdo, pautada em Bardin (2004). Assim, as análises são apresentadas a partir das categorias que emergiram desse trabalho de campo. Reitero, no entanto, que a análise de conteúdo não foi considerada e trabalhada como modelo exato e rígido. Mesmo Bardin (2004) rejeita esta ideia de rigidez e de completude, deixando claro que a sua proposta da análise de conteúdo acaba oscilando entre dois polos que envolvem a investigação científica: o rigor da objetividade, da cientificidade, e a riqueza da subjetividade. Nesse sentido, a técnica tem como propósito alcançar o rigor científico necessário, mas não a rigidez inválida, que não condiz mais com tempos atuais, antes trazendo diálogos que contribuam para a produção do conhecimento que atenda aos anseios da contemporaneidade (MOZZATO e GRZYBOVSKI, 2011).

Assim, no próximo tópico, apresentarei as categorias que emergiram sobre o lugar do trabalho com a escrita nas classes pesquisadas.

\section{Práticas de escrita nas classes da EJAI: o ditado e a cópia}

Em nosso contexto contemporâneo e urbano, os sujeitos da EJAI vivem em uma sociedade letrada. A escrita se faz necessária para atividades cotidianas, como assinar o próprio nome em um documento, escrever uma mensagem no smartphone, em redes sociais, escrever uma redação para um processo seletivo, entre outras aparições. Soares (2000) nos diz que, a cada momento, multiplicam-se as demandas por práticas de leitura e de escrita, não só na chamada cultura do papel, mas também na nova cultura da tela, com os meios eletrônicos.

\footnotetext{
${ }^{3}$ No ano de 2012, os professores da rede estadual de ensino aderiram a uma greve que durou 115 dias. Essa greve alterou o calendário escolar dos anos subsequentes, que se regularizou apenas a partir do ano letivo de 2015.
} 
Entretanto, na escola pesquisada, encontrei outras motivações para a realização da escrita, como escrever em um documento o nome do mês que se desejava tirar férias, nomes de produtos cosméticos, poemas, cartas de amor, reivindicações para a gestora da escola atividades de escrita que permeavam o cotidiano dos discentes e que só a produção textual poderia garantir que fossem elaboradas. No trabalho de campo, percebi também que todos os discentes sabiam escrever o próprio nome, mas nas salas de aula as atividades de escrita eram restritas e eram parcos os exercícios de produção textual. Seguindo, talvez, uma tradição gramatical advinda de escolas frequentadas anteriormente, a vibração dos discentes acontecia quando estes escreviam uma palavra grafada corretamente, em termos de ortografia. Vi prioritariamente três atividades envolvendo a escrita, que elencam as categorias trabalhadas neste artigo: 1 - O ditado de palavras, que se configurou como a atividade preferida pelos discentes no que se refere ao exercício de escrever; 2 - Atividades de cópia do quadro para o caderno; 3 - A entrega de figuras com um traço ao lado para que os discentes colocassem o nome do objeto representado.

Vejamos o que os discentes falaram sobre seu próprio aprendizado quando questionei em que atividade de escrita eles sentiram que mais aprenderam a escrever:

No ditado eu aprendo as letras... Formar as palavras com algumas letras que estão faltando. (Educando A, Entrevista, 2014)

Mesmo assim eu errando é quando ela passa palavra pra gente escrever. É ditado, aí mesmo assim errando eu olbo e vejo que eu como poucas letras, mas como letra e escrevo assim comendo as letras.

(Educanda C, Entrevista, 2014)

O ditado. O ditado me ajuda muito porque vejo como as palavras são escritas e assim até ensino ao meu filho as palavras corretas.

(Educanda D, entrevista, 2014)

No ditado eu vou aprender até mesmo escrever certo, as palavras certas, entender melhor.

(Educando F, Entrevista, 2014)

Eu estou melhorando na escrita com a atividade do ditado de palavras.

(Educanda B, Entrevista 2014)

Eu gosto mais do ditado. Porque en quando estudava o que a professora passava mais era ditado de palavras, e ai en peguei a gostar das palavras que a professora prescrevia pra gente 
fazer, palavras de nomes de pessoas, nomes de casas próprias, nomes próprios [...] muitas palavras assim com dificuldade e ai eu ficava me dedicando pra aprender e ai eu comecei a gostar, comecei a me dedicar e en gosto muito de ditado.

(Educanda H, Entrevista, 2014)

Eu gosto do ditado, porque assim en aprendo a escrever as palavras certas.

(Educando G, Entrevista, 2014)

Para escrever en gosto de ditado. (Educando I, Entrevista, 2014)

Percebamos, pelos depoimentos acima, que, dos quatorze discentes que entrevistei, oito pontuaram o ditado como a principal atividade que os auxilia no exercício de aprendizagem da escrita. O enfoque do saber escrever se pauta na escrita ortograficamente correta. Ressalto que o ditado é uma atividade importante no exercício de aprendizado da ortografia e conhecimento de vocábulos. No entanto, ele não se configura como atividade de produção textual que trate, por exemplo, de aspectos como coesão, coerência e do reconhecimento da escrita como instrumento de comunicação e preservação da memória. Nesse aspecto, conforme vimos nas observações das aulas, as atividades de escrita são restritas e os discentes respondem no momento da entrevista a sua predileção de grafia com base nas atividades, às quais eles têm acesso nas práticas escolares. Kleiman (2005) nos provoca a ensinar aos discentes práticas de letramento. Em se tratando da escrita, ela propõe atividades de troca de cartas, de comentar notícias no papel, de escrever informações pertinentes para a realização de uma tarefa, entre outras propostas. No que diz respeito a esta pesquisa, proponho uma escuta dos discentes sobre suas demandas e desejos de escrita. Assim, é interessante que as práticas de letramento partam, especialmente, dessa atividade de escuta sensível, ao mesmo tempo em que se proponha práticas pedagógicas que ampliem o repertório de atividades escritas, despertando, talvez, e por consequência, gosto e hábito pelas atividades de produção textual.

Fiquei instigada a conhecer mais sobre a compreensão desses discentes acerca do processo de escrita, especialmente pensando nos usos sociais desse aprendizado. No geral, eles consideram escrever uma atividade muito difícil e não se percebem como sujeitos que podem produzir textos, embora exista esse desejo, e, em alguns casos, até os produzam. No trabalho de campo encontrei, por exemplo, um discente que é poeta. Perguntei como ele faz para decorar os próprios poemas. Ele diz que memoriza ou escreve com o auxílio de alguém. Nesse aspecto, ressalto as contribuições de Lerner (2002) sobre os comportamentos escritores, no intuito de refletir sobre eles e, num exercício dialógico, pensar em práticas de escrita 
na EJAI que dialoguem com as que são realizadas por qualquer escritor. Para a autora, atividades como o planejamento, a textualização, as atividades de revisão, a previsão dos futuros leitores etc. devem integrar o trabalho de formação de escritores.

As atividades com comportamentos escritores precisam também adentrar nas salas de aula para que o próprio processo de aprendizado da escrita seja compreendido. Muito comumente, em campo, ouvi os discentes dizendo que "comiam letras", que não sabiam a grafia de determinadas palavras e, por vezes, diziam que a cabeça não estava "mais boa" para aprender a escrever, que não tinham tempo para fazer atividades em casa. Assim, mais uma vez, reitero a necessidade de trabalho com comportamentos escritores nas salas de aula como conteúdos que precisam ser abordados. $\mathrm{O}$ aprendizado da escrita não se resume à escrita da grafia correta de uma palavra; ele acontece quando esta se torna uma ferramenta de comunicação e preservação da memória. Comunicação com outros sujeitos, ou consigo próprio. Para que isso se concretize, as concepções sobre o aprendizado da escrita precisam ser ampliadas e os sujeitos da EJAI, ouvidos, pois, em suas falas, expressa-se desejos e demandas de aprendizagem que podem possibilitar uma ressignificação da educação escolar ofertada para a EJAI. Do mesmo modo que os escutamos, precisamos apresentar possibilidades de ampliação das práticas escritoras. Vejamos uma fala interessante de um dos discentes pesquisados:

Eu acho que deveria trabalhar mais a escrita e as palavras porque é onde tem o desenvolvimento do... meu desenvolvimento mais é isso aí porque se colocar no quadro uma coisa eu não vou saber [...] Tem que trabalhar a escrita de outro jeito, sei lá...

(Educando A, Entrevista, 2014)

Reitero, com a fala do aluno, a necessidade de escuta dos sujeitos da EJAI, da compreensão das percepções que esses sujeitos têm sobre seu processo educativo. Urge conhecer esses "outros" sujeitos que estão nos espaços educativos formais para que possamos construir "outras" pedagogias que dialoguem e façam com que os sujeitos avancem no aprendizado. Ainda é referência para nós a experiência de alfabetização proposta por Paulo Freire na década de 1960 do século passado. No II Encontro Internacional de Alfabetização ${ }^{4}$ de Adultos, a pesquisadora Nilcéa Lemos Pelandré, da Universidade Federal de Santa Catarina, questionou a experiência de Angicos e foi encontrar esses sujeitos alfabetizados naquela época para saber se estes ainda sabiam ler e escrever. O diálogo com esses sujeitos permitiu

\footnotetext{
${ }^{4} \mathrm{O}$ encontro ocorreu na cidade do Salvador, entre os dias 8 e 11 de novembro de 2015, e foi promovido pela Universidade do Estado da Bahia. Mais informações no site: http://www.alfaeeja.com/.
} 
à pesquisadora compreender que houve aprendizado significativo condizente com o contexto em que foi aplicado e os educandos foram motivados a aprender, e aprenderam a leitura e a escrita, ancorados em práticas de letramento que atendiam aos seus interesses. Arroyo (2011) destaca que na pedagogia da prática da liberdade e do oprimido, o foco do aprendizado é o sujeito, num exercício de reeducação da sensibilidade pedagógica para captar os oprimidos como sujeitos da sua educação, de construção de saberes, conhecimentos, valores e cultura. Assim, neste trabalho, apresento os dizeres dos educandos com o objetivo de repensarmos e reinventarmos a tradição escolar, que ainda persiste na realização de práticas que não garantem o efetivo aprendizado da escrita. O desafio é ultrapassarmos os discursos de que os educandos não aprendem e pensar, juntamente com eles, em propostas pedagógicas inovadoras que garantam o aprendizado. Nesse aspecto, não precisamos necessariamente reaplicarmos a experiência de Freire, mas nos ancorarmos em seus princípios políticos, pedagógicos e humanitários e construirmos práticas que garantam um aprendizado de escrita condizente com as demandas contemporâneas. Vejamos algumas falas dos discentes da EJAI sobre seus desejos de aprendizado:

Lá na loja onde eu trabalho como segurança os vendedores trabalham utilizando computador. A Escola devia ensinar a mexer no computador, tem laboratório e tal.

(Educando, B, Entrevista, 2014)

Aqui na escola está trabalhando muito com conta, armar conta, fazer conta, isso eu já sei, entendeu? É, conta eu "vou embora". Não estou precisando de conta, estou precisando é de escrever e ler.

(Educando F, Entrevista, 2014) Acho que a gente devia trabalhar com computador, biblioteca, aprender a fazer pesquisa, a estudar melhor.

(Educando, G, Entrevista, 2014)

Eu queria escrever uma carta para ela [referindo-se à esposa], mas como? Nem eu sei escrever, nem ela sabe ler.

(Educando A, Entrevista, 2014)

Percebamos que um caminho possível para construirmos uma escola que ensine a escrever é também ouvir os educandos nas suas demandas e desejos de aprendizagem, inovando, pensando em práticas pedagógicas que dão resultados. A atenção à presença dos sujeitos, saber onde estes trabalham, como se entendem como sujeitos na escola e em outros espaços sociais é um caminho possível para a construção de uma educação escolar para a EJAI que dialogue com os usos sociais da leitura e da escrita. A educação para EJAI precisa romper com a tradição que nasceu com a missão colonialista de homogeneizar o mundo, 
obliterando as diferenças culturais (SANTOS, 2005), e se reconstruir através do diálogo e consideração das vozes dos sujeitos que a constituem.

Assim, dentro de uma prática contextualizada, é importante que os discentes se sintam agentes do processo de construção do conhecimento. Ao ouvirmos o que eles têm a nos dizer e utilizando esses dizeres na execução de nossas aulas, possivelmente as práticas de escrita serão mais exitosas.

Trago ainda, para ampliar a discussão, uma fala da professora B, que, timidamente, me confessa que trabalha a aprendizagem da leitura e também da escrita a partir dos métodos sintéticos. Ela me diz o seguinte: "Se o aluno ainda não sabe escrever, como colocar um texto? coloco silabas, palavras, para depois virem outras coisas... ampliar...” (Professora B, entrevista, 2015)

Efetivamente, interagir com uma docente que parte de métodos sintéticos para alfabetizar foi para mim um exercício difícil e desafiador. Quis, no entanto, compreender o outro sobre o ponto de vista do outro. A professora me disse que percebia avanços no aprendizado quando trabalhava a leitura e a escrita partindo de palavras. Os textos propostos nos livros eram muito grandes e, para ela, não fazia sentido trabalhar esses textos longos com discentes que ainda não sabiam ler. Nem eles podiam responder perguntas dos textos que demandavam respostas extensas. Assim, ela começava das unidades menores para as maiores e dizia que o aprendizado dos discentes melhorou com essa abordagem pedagógica.

Quero destacar que o método de trabalho do docente não é a discussão mais importante proposta neste trabalho. Por isso, neste caso, a problematização acontece pelo fato de os sujeitos, por ainda não serem alfabetizados, não terem acesso, na educação escolar, a textos, nem a produções textuais - apenas às atividades de escrever palavras, embora saibamos que, com essas atividades, não se aprende a produzir textos. A escuta sensível e a ousadia corajosa de se pensar outros modos de ver e fazer a EJAI constituem o foco central da discussão desta pesquisa. Proponho, portanto, reflexões para repensar a EJAI a partir de um contexto concreto, para que possamos avançar no exercício de construção do conhecimento e de práticas pedagógicas nessas classes.

No que se refere, ainda, ao trabalho com escrita, foram recorrentes os dizeres sobre a cópia em sala de aula. Alguns discentes ressaltaram a importância de copiar certinho do quadro para o caderno, escrever com letra cursiva, e enxergar no próprio caderno o resultado dessa atividade.

É importante mencionar que a cópia tem seu lugar no exercício de escrita. Copiamos poemas em nossos cadernos, fazemos fichamentos de textos teóricos, copiamos as ideias centrais dos autores. Entretanto, limitar a atividade de escrita à cópia é privar o sujeito de 
aprender a falar sobre o mundo de um outro jeito. Privamos os sujeitos de registrarem suas memórias, ampliar a participação cidadã na sociedade letrada.

Entretanto, vindos de uma tradição escolar que precisa ser rompida, os discentes ainda enxergam a cópia do quadro como uma atividade que lhes ensina a escrever. É importante destacar que as professoras pesquisadas não colocavam no quadro grandes textos para que os discentes copiassem. A própria correção do ditado de palavras ou as repostas a uma atividade proposta eram colocadas no quadro e os discentes copiavam atentamente, o que sempre tomava muito tempo da aula. Vejamos, a esse respeito, uma problematização já apontada por um dos próprios discentes:

Escrever também eu tenho vontade de saber tirar do quadro, mas só que eu não tenho condições por causa da minha vista. Eu forço muito a vista, então não tenho condição de tirar do quadro... ... Às vezes eu copio mais não sei o que estou escrevendo, se mandar ler eu não vou saber ler, entendeu?

(Educando A, Entrevista, 2014)

O educando nos traz uma das principais problematizações do trabalho com a cópia. O discente copia o que está posto no quadro para o caderno e na sequência não saberá ler o que escreveu. Ressaltamos que a atividade de cópia, assim como o ditado, não se configura como atividade de produção textual, e, por vezes, se constitui como a finalização de uma atividade de escrita sem que haja reflexões por parte dos aprendentes sobre as compreensões advindas do trabalho com esse texto.

Assim, o conhecimento de outras atividades de escrita, especialmente as que envolvem a produção textual, torna-se necessário para ampliar o repertório de conhecimento sobre a linguagem escrita e os aspectos que se referem aos usos sociais desse conhecimento, fazendo emergir a necessidade de serem discutidos em sala de aula e materializados nas propostas didáticas sobre as atividades de escrita.

Reitero, conforme apontando por Marcuschi (2008), que é de fundamental importância o trabalho com o mesmo gênero textual dentro do eixo leitura, escrita e oralidade para que as compreensões se construam a partir da leitura e discussão de uma proposta, e a atividade de produção se ancore nas discussões que outrora se desenvolveram em sala de aula, preferencialmente usando os mesmos textos ou outros correlatos.

No que se refere ao uso de imagens para escrever o nome dos objetos ao lado, tratase de uma atividade proposta em cartilhas e que, no geral, eram descontextualizadas, visto que as palavras apresentadas faziam parte do universo infantil, tais como: vovó, vovô, bebê, xarope, peteca, entre outras. A atividade também se pauta apenas na escrita das palavras pelos 
discentes e posterior correção no quadro pela professora. A atenção dos discentes e os destaques dados pela professora referiam-se à escrita correta das palavras e à exploração das semelhanças e diferenças entre elas, como o que difere a escrita de vovô da de vovó.

É importante destacar que o status social de saber escrever não fez parte da trajetória de vida desses discentes e, pelos diálogos nas entrevistas formais e informais, nem de seus familiares. Por vezes, eles desejam pouco no que se refere ao aprendizado da escrita, por não terem referenciais escritores em seu cotidiano. As experiências dos programas de alfabetização no Brasil, no geral, limitaram e ainda limitam as próprias possibilidades de aprendizado da escrita dos discentes ${ }^{5}$. Assim, e talvez decorrente dessas formas de trabalhar a escrita na EJAI, as propostas didáticas que não propiciam ampliação de repertórios leitores e escritores vão se constituindo, e esse sujeito discente da EJAI não se torna escritor de textos mais elaborados, como uma dissertação, e às vezes nem dos simples, como é o caso de um bilhete.

Assim, quero ressaltar que as atividades de aprendizado da escrita nas classes da EJAI, de um modo geral, demandam ressignificações para que esses sujeitos possam se enxergar como pessoas que podem produzir textos, por estudar os processos de produção textual. Mesmo os livros didáticos que têm em suas propostas as atividades de letramento, as produções textuais precisam ser reinventadas, ampliando-se as propostas de letramento, tornando os sujeitos produtores dos mais variados textos. Desse modo, no próximo subtópico, apresentarei alguns achados referentes ao aprendizado da escrita que podem nos dar pistas sobre outras formas de lidar com esse aprendizado na EJAI, podendo também expandir a qualidade da educação ofertada para essa modalidade de ensino.

\section{Alguns achados no aprendizado da escrita}

As palavras só têm sentido se nos ajudam a ver o mundo melhor. Aprendemos palavras para melhorar os olhos. Rubem Alves

As atividades de escrita presentes nas classes da EJAI em que realizei a pesquisa, de modo geral, me fizeram refletir e pensar em estratégias de mobilização para ampliar esse aprendizado, buscando respaldo nos usos sociais e nas necessidades subjetivas dos sujeitos pesquisados. No entanto, percebo que o trabalho de pesquisa, especialmente uma etnopesquisa, é compreender os sujeitos, suas vivências e posicionamentos, construindo, a partir da

\footnotetext{
${ }^{5}$ A matriz de referência do Programa Brasil Alfabetizado, por exemplo, apresenta descritores de aprendizado da escrita bem simplórios e que, no geral, não possibilitam a formação de um sujeito escritor. A matriz encontrase disponível no site: http://portal.mec.gov.br/secad/arquivos/pdf/brasilalfabetizado/matriz_referencia.pdf. Acessado em: 04/12/2015.
} 
escuta e do diálogo, conhecimentos - tal como Rubem Alves, quis aprender mais as palavras para melhorar as visões sobre esses sujeitos e suas práticas educativas, melhorar o modo de enxergar a educação que já se faz na EJAI. Nisso, quero apresentar alguns achados no trabalho de campo que nos ajudaram a perceber que as discussões sobre os usos sociais da escrita timidamente adentram nas escolas e, de algum modo, dialogam com algumas práticas. Penso que estas, em sendo exitosas, serão ampliadas e replanejadas, renovando, assim, a educação ofertada para a EJAI.

Lembro-me de um dia que chego na escola e há toda uma movimentação no trabalho com uma espécie de treino para as eleições de presidente da república. Nessa atividade, os “discentes possíveis candidatos" apresentavam seus discursos num texto escrito. A atividade trabalhou com o eixo leitura, escrita e oralidade, pois os discentes precisaram pesquisar questões pertinentes para escrever seu discurso. Este, depois de pronto, foi lido para os colegas dentro de uma fala que demandava formalidade, visto que se tratava da emissão de um discurso político. Os discentes emitiam seus discursos a partir de preocupações individuais e coletivas. Uma das candidatas falou a respeito do cumprimento da lei Maria da Penha, que já existe, mas cuja efetivação ainda é frágil pois, os acusados não permanecem presos e ainda ameaçam suas companheiras; outro candidato falou a respeito da ampliação das oportunidades de emprego, pois acredita que, com mais pessoas empregadas, haverá menos violência. Esses exercícios de produção de textos mais elaborados, que demandam pesquisas e revisões, carecem adentrar cada vez mais nas classes da EJAI, visto que são adultos se escolarizando e a importância do trabalho com atividades escritas que se desenvolvem em sala de aula precisam emergir.

Para se ampliar o interesse, gosto e hábito pela escrita, é necessário que se tenha um repertório variado de possibilidades para desenvolver essas práticas na escola e em outros espaços. Mais uma vez, ouvir os discentes torna-se de decisivo para que práticas inovadoras se concretizem.

Outra situação interessante, que não vivenciei, mas que foi trazida pela professora $A$, foi a constituição de grupos de estudo pelos estudantes que têm como propósito aprender para passar de ano e colher insumos decorrentes do aprendizado escolar. Geralmente, os discentes que conseguem avançar firmam parcerias com colegas na escola e fora dela. Aprendem juntos a estudar, realizar pesquisas, dialogar com colegas de séries mais avançadas, vivenciar uma cultura escolar com o objetivo de conseguir progredir nos aprendizados. Como o tempo para estudos é um fator que interfere nessa vivência de práticas de leitura e escrita fora da escola, esses estudantes reuniam-se diariamente, um tempo antes de iniciar as aulas, 
e estudavam coletivamente, ajudando um ao outro e propondo aos professores que, mesmo apresentando algumas dificuldades na escrita ortográfica, eles poderiam passar de ano e vivenciar outras aprendizagens dentro da escola e em séries mais avançadas.

Assim, mesmo educandos que não sabiam como estudar foram construindo rotinas de estudos e superando, dentro do seu tempo, dificuldades na construção de textos escritos, conseguindo a aprovação. Assim, a própria professora foi dialogar com os docentes do Tempo Formativo II, sensibilizando-os para que acolhessem os discentes, mesmo os que apresentavam dificuldades na produção textual, visto que eles angariaram esforços para aprender. Solicitou também que eles atentassem para o trabalho pedagógico com os discentes da EJAI, considerando a história de exclusão educacional que esses sujeitos já vivenciaram, tornando a escola, que é centro de formação de adultos, um espaço de inclusão.

Esse diálogo com a professora me fez refletir sobre a importância de uma escola vivaz, uma escola que a todo momento dialogue e possibilite práticas de letramento, estratégias de leitura e escrita, e um diálogo constante com a vida desses sujeitos, com as demandas cotidianas e com a possibilidade de emancipação, de mudanças de vida. A educação corajosamente inovadora, proposta por Arroyo (2011), de algum modo vem se construindo, com respaldo no diálogo, na escuta e na percepção da educação que é necessária para se garantir o aprendizado desses múltiplos sujeitos. Os discentes que prosseguem em seus estudos nessa escola já planejam fazer concurso público, cursar uma universidade, enfim, dialogam com outras possibilidades educativas além da educação básica.

No próximo tópico, apresento as considerações finais deste trabalho.

\section{Considerações finais}

Escrever é atribuir sentidos e significados para as nossas vivências pessoais e profissionais, para aspectos dizíveis e, por que não afirmar, indizíveis, das nossas experiências "Uso as palavras para compor meus silêncios", disse Manoel de Barros. Roland Barthes afirmou que "escrever é sacudir o sentido do mundo"7. Timidamente, neste trabalho, quis apresentar algumas reflexões sobre o aprendizado da escrita em classes da EJAI, especialmente problematizando a questão do ditado e da cópia como principais atividades destinadas a esse fim. Nessa perspectiva, proponho reflexões sobre o que seriam atividades de produção

\footnotetext{
6 Trecho do poema "O apanhador de desperdícios". Livro As memórias inventadas. São Paulo: Planeta do Brasil, 2010.

${ }^{7}$ BARTHES, Roland. Aula. 6. ed. São Paulo: Cultrix, 1980.
} 
textual e os modos de tornar os discentes da EJAI sujeitos que possuem o hábito e gosto pela escrita em consonância com as demandas sociais e individuais.

A presença do ditado e da cópia como principais atividades de escrita no contexto pesquisado demanda reflexões sobre a formação escritora desses discentes e instiga novos modos de pensar e fazer a produção textual nessas classes.

Ao ouvir os dizeres dos educandos, percebo que devemos nos atentar ao perfil desses sujeitos, que têm posicionamentos críticos sobre seu próprio processo de aprendizado, repensando atividades que lhes possibilitem contatos com as práticas de letramento. No entanto, essas práticas demandam ampliação de saberes e atenção às necessidades contemporâneas que esses próprios sujeitos vivenciam em seus cotidianos, formando, assim, estudantes como cidadãos da cultura escrita.

Assim, dos diálogos com os educandos da EJAI, saio desejosa de que eles ampliem suas práticas de letramento, reconheçam, aprendam e pratiquem os comportamentos escritores. Espero que aprendam a consultar palavras desconhecidas, substituir uma palavra de que não sabem a grafia por uma outra que dê conta da significação; a reler o texto já escrito e a fazer as revisões necessárias e, especialmente, se percebam como sujeitos que constroem textos e que são plenamente capazes de se apropriar de comportamentos escritores, modificando-se, aprendendo a estudar sozinhos e em grupo, alcançando a importância desse aprendizado para expansão da cidadania.

Olhar os educandos nos olhos, agregar e perceber as demandas específicas e as heterogeneidades existentes nas diversas escolas e comunidades é um exercício de estudo, humanização e pesquisa que precisa adentrar nas discussões da EJAI nos tempos atuais. Tenho consciência da complexidade dessa proposta. No entanto, urge discutirmos, nas instituições escolares, as relações de alteridade e praticá-las na convivência e respeito pelo outro, no intuito de melhorarmos as relações de respeito e as convivências na atualidade.

\section{WRITING PRODUCTION AT YOUTH, ADULT AND SENIORS EDUCATION PROGRAM: PROBLEMATIZATIONS}

\footnotetext{
ABSTRACT: This article aims to provoke reflections concerning writing production in Youth, Adult and Senior Education Program (EJAI). The article is the fragment of a doctorate research that sought to understand some of the learners and teachers' perceptions about the reading, writing and orality learning processes at EJAI, considering the peculiarities of the individuals, and establishing connections with the social uses of the language. In order to develop this study, an ethnographic study was carried out in a public state school in Salvador. Semi-structured interviews were conducted with students and teachers, in addition to class observation. The results of the research enabled the understanding that rewriting and dictation stand out as writing practices in the classes. Nevertheless, an urge for more contextualized writing practices arises, although timidly. This article is expected to contribute to the development of a more accurate perspective concerning the teaching of writing at EJAI, as well as highlight the importance of listening carefully to the individuals, when reconsidering the education provided by this teaching modality.
} 
Keywords: Writing production at EJAI. Dictation. Rewriting. Contextualized practices.

\section{REFERÊNCIAS}

ALVES. Rubens. $A$ arte de educar. Disponível em: https://psicologiaacessivel.net/2015/07/15/a-arte-de-educar-um-lindo-texto-de-rubem-alves/. Acesso em: $12 / 02 / 2017$.

ANDRADE. Carlos Drummond. Antologia poética: organizada pelo autor. $37^{\mathrm{a}} \mathrm{ed}$. Rio de Janeiro: Record, 1997.

ARROYO. Miguel. Educação de jovens-adultos: um campo de direitos e de responsabilidade pública. In: SOARES, Leôncio. GIOVANETTI. Maria Amélia. GOMES. Nilma Lino. Diálogos na educação de jovens e adultos. 4ª ed. Belo Horizonte: Autêntica, 2011.

BARDIN, Laurence. Análise de conteúdo. Tradução: Luís Antero Reto e Augusto Pinheiro. 3. edição. Lisboa: Edições 70, 2004.

FERREIRO, Emilia. Reflexões sobre alfabetização. São Paulo: Cortez, 1995.

KLEIMAN. A. B. Preciso "ensinar" o letramento? Não basta ensinar a escrever?. CEFIEL. IEL. UNICAMP, 2005.

LERNER. Delia. Ler e escrever na escola: o real, o possível e o necessário. Porto Alegre: Artemed, 2002.

MARCUSCHI. Luiz Antonio. Produção textual, análise de gêneros e compreensão. São Paulo: Parábola Editorial, 2008.

MOZZATO. A. R. GRZYBOVSKI. Análise de Conteúdo como Técnica de Análise de Dados Qualitativos no Campo da Administração: Potencial e Desafios D.RAC, Curitiba, v. 15, n. 4, pp. 731-747, Jul./Ago. 2011

SANTOS. Boaventura de Souza. Colonialidade do poder, eurocentrismo e América Latina.In: LANDER, E. (org). A colonialidade do saber: etnocentrismo e ciências sociais. Perspectivas Latinoamericanas. Buenos Aires; Clacso, 2005.

SOARES. Leôncio. O educador de jovens e adultos e sua formação. Educ. rev. no.47 Belo Horizonte June 2008. Disponível em: http:/ / www.scielo.br/scielo.php?script=sci_ arttext\&pid=S0102-46982008000100005. Acesso em: 08/05/2015.

SOARES. Magda. Aprender a escrever, ensinar a escrever. Disponível em: http://www.crmariocovas.sp.gov.br/pdf/ideias_28_p059-075_c.pdf, 2000, acessado em 12/09/2015.

Recebido em: 21/02/2021.

Aprovado em: 14/06/2021. 